\title{
New species of the rare genera Dentigaster Zettel, 1990 (Hymenoptera, Braconidae, Cheloninae) and Minanga Cameron, 1906 (Sigalphinae) from French Guiana
}

\author{
M. J. Sharkey ${ }^{1, \dagger}$, Y. Braet ${ }^{2, \ddagger}$ \\ I Department of Entomology, University of Kentucky, Lexington KY 40546-0091, USA 2 Département d'en- \\ tomologie, Institut royal des Sciences Naturelles de Belgique, Rue Vautier 29, B- 1000 Bruxelles, Belgium; Unité \\ d'Entomologie fonctionnelle et évolutive, Gembloux Agro-Bio Tech, Université de Liège, Passage des Déportés 2, \\ B-5030 Gembloux, Belgium \\ † urn:lsid:zoobank.org:author:77B8EC3A-442C-4A7A-AF85-A31C27E257F2 \\ † urn:lsid:zoobank.org:author:C1A1006D-C170-430D-9D9F-27AB0878DDDD \\ Corresponding author: M. J. Sharkey (msharkey@uky.edu) \\ Academic editor: G. Broad | Received 7 December 2011 | Accepted 20 February 2012 | Published 23 March 2012 \\ urn:lsid:zoobank.org:pub:0D447DB6-41D3-4FD4-A5FF-2739D8E8EF13 \\ Citation: Sharkey MJ, Braet Y (2012) New species of the rare genera Dentigaster Zettel, 1990 (Hymenoptera, Braconidae, \\ Cheloninae) and Minanga Cameron, 1906 (Sigalphinae) from French Guiana. Journal of Hymenoptera Research 25: \\ 93-102. doi: 10.3897/JHR.25.2519
}

\begin{abstract}
Two new species, recently discovered in French Guiana, are described. Minanga angelus sp. $\mathbf{n}$., is the second species from the New World and the first Neotropical species. Dentigaster brullei $\mathbf{s p .} \mathbf{n}$. is the seventh described species of the genus. Identifications keys for both genera are updated.
\end{abstract}

\section{Keywords}

identification key, French Guiana, insect, Neotropics, parasitoid

\section{Introduction}

The genus Dentigaster was proposed and included in the tribe Pseudophanerotomini Zettel, 1990 by Zettel (1990). This tribe and its members are found in the New World with all but one species restricted to the Neotropics. Zettel (1990) erected this new ge-

Copyright M. J. Sharkey, Y. Braet. This is an open access article distributed under the terms of the Creative Commons Attribution License 3.0 (CC-BY), which permits unrestricted use, distribution, and reproduction in any medium, provided the original author and source are credited. 
nus on the basis of the following putative apomorphies: antennal sockets in the upper part of head, maxillary palpus long, notauli (nearly) absent, shape of carapace rather vaulted, carapace apically largely emarginated, carapace with apical tooth.

Only four species were described by Zettel $(1990,1992)$ but their biology is unknown, other than the likelihood that they are egg-larval parasitoids of lepidopteran larvae, as in all known members of Cheloninae. The only previous species recorded from French Guiana is Dentigaster warana Braet \& Fretey (1997) collected in the coastal area, on grassland between the beach and the mangrove. Our new record comes from the Nouragues Reserve located in the country's interior $\left(4^{\circ} 02^{\prime} \mathrm{N}, 52^{\circ} 41^{\prime} \mathrm{W}\right)$.

The genus Minanga was unknown in the New World until M. achterbergi Sharkey (2004) was discovered in northern Mexico. The species described here represents the second species in the New World and extends the distribution of the genus into the Neotropics. The biology is unknown other than the probability that it is a koinobiont endoparasitoid of larval Lepidoptera, as in other members of the subfamily (Shaw and Quicke 1990; Sharkey and Janzen 1995).

\section{Material and methods}

The two species described in this paper were collected in a Malaise trap which was operated during the entomological survey of the Nouragues Reserve (French Guiana) by the "Société Entomologique Antilles-Guyane". The Malaise trap was placed at N4 02.368-W52 40.429 by the SEAG association and run from the 21/VII/2009 - 19/ VII/2010. During this year of collecting, 636 specimens of Braconidae were collected but only one specimen of each of our new species.

For the morphological terms used in this paper see van Achterberg (1993). The specimens are deposited in collections of the "Institut Royal des Sciences Naturelles de Belgique, Département d'entomologie, Bruxelles » (IRSNB).

\section{Results}

\section{Descriptions}

\section{Dentigaster brullei Braet \& Sharkey, sp. n}

urn:lsid:zoobank.org:act:249B3C88-9CB6-467D-A9DC-0E887313A051

http://species-id.net/wiki/Dentigaster_brullei

Holotype. Female.

Diagnosis. This species is easily distinguished from D. barbarella Zettel, 1990 by its whitish basal flagellomeres (vs. yellowish-orange), the head and thorax fully blackish (vs. orange), and the carapace with several coarse, parallel apical carinae (vs. regularly rounded) in dorsal view. The new species is closer to D. walteri Zettel, 1990 or $D$. 
tenuiventris Zettel, 1990 and it can be distinguished from these by its size (6 mm vs. $+/-4 \mathrm{~mm}$ ), the shape of coarse rugae at the distal apex of the metasoma (with always the same width along their length vs. with some enlargements at their apex), and by the color of the basal flagellomeres (whitish vs. brownish).

Size. Body length $6 \mathrm{~mm}$, fore wing length $4.2 \mathrm{~mm}$.

Color. The first two flagellomeres whitish, the following dark brown. Scapus dorsally brown and ventrally light yellowish. Head fully dark brown; upper part of face and face at the inner margin of eyes lighter (whitish). Mesosoma fully dark brown. Fore wing with strongly infuscate bands; with a transverse white strip at level of parastigma, apex of fore wing and hind wing lightly infuscate. Stigma and veins brown. Fore and mid femur except basally and apically, hind coxa, hind femur, apical 2/3 of hind tibia dark-brown. Outer hind tibial spur, hind tarsomeres 3-5, mid tarsomeres 3-5, all light brown. All remaining parts of legs whitish. Carapace brown except white median patch basally (covering median part of T1 and basal part of T2), apical sternites brown. Ovipositor sheath yellowish.

Head. Head $0.89 \times$ as wide as its median length. Antennal socket inserted close to top of eyes in lateral view. Antenna with 37 flagellomeres. Scapus 1.72 times as long as maximally wide, longer than first flagellomere. First flagellomere 3 times as long as wide, longer than second one. Penultimate flagellomere as long as wide, 0.05 times as long as first flagellomere, shorter than apical segment. Flagellomeres gradually decreasing in size from base to apex. Last 10 apical flagellomeres without placodes on all sides. Placodes entirely missing on apical flagellomeres. Eye 1.4 times length of temple (in dorsal view), 1.48 times as high as broad, with short and sparse setae. Clypeus flat in lateral view, with more or less convex lower margin, with two small apical teeth medially, its surface smooth. Upper margin of clypeus with large punctures, dorsal surface of clypeus densely punctate. Malar suture absent. Malar space equal to basal width of mandible, $0.32 \times$ eye height. Face strongly convex in lateral view, surface punctate (medially finely punctuate, laterally largely smooth and punctate) with short, sparse setae (long setae present on mandible). Temple not swollen in dorsal view, its surface coarsely rugulose/punctate, with short, sparse setae. Frons transversely striate, concave, with a weak carina between antennal sockets, without lateral carina. POL 1.67× ocellar diameter, 3× OOL. Vertex striate, with faint, weakly transversely rugulose punctures and short sparse setae. Occipital carina present, complete, joining hypostomal carina before mandible.

Mesosoma. Pronotum striate/costate ventrally and dorsomedially, punctate dorsolaterally (large punctures becoming small and very dense at upper margin), dorsally without modifications. Pronotal furrow absent. Mesosoma $1.59 \times$ as long as wide in lateral view, $1.51 \times$ as long as wide in dorsal view. Mesoscutum sharply raised anteriorly, at right angle with pronotum, medioanteriorly dull (impunctate), median lobe without median groove anteriorly. Mesoscutum with sparse, short setae. Surface of mesoscutum medially, near scutellar sulcus, largely longitudinally punctate, surface rather smooth between punctures. Notauli entirely absent. Scutellar sulcus 4x as long as wide, $1.33 \times$ as long as scutellum, its surface smooth. Scutellar sulcus with 7 complete carinae. Scutellum rounded laterally, flattened in lateral view, its surface 
smooth and punctate (large punctures widely spaced). Subalar groove punctate. Mesopleuron entirely areolate with sparse, short setae. Sternaulus absent. Ventral surface of mesopleuron more or less punctate (regularly spaced). Propodeum $0.33 \mathrm{x}$ as long as mesosoma (in dorsal view), its surface areolate to largely punctate, carinated areas completely absent but mediolongitudinal carina anteriorly present. Propodeum vertical posteriorly, with sparse, short setae. Propodeum with four pointed rounded angles, more developed laterally than medially (rather tuberculate laterally); median tubercles present and short (as high as wide). Lateral tubercles of propodeum 0.5 times their maximum transverse width, propodeal tubercles straight, with rounded apices. Surface of metapleuron largely punctate, with short, sparse setae. Metapleural flange absent. Wings: pterostigma $4.44 \times$ as long as wide. Marginal cell of fore wing distally closed. Vein $r 0.7 \times$ as long as vein $3-S R, 0.16 \times$ as long as vein SR1, $0.25 \times$ as long as vein $2-S R$. Vein 2-SR of fore wing present. Vein 1-SR+M present, straight. First discal cell of fore wing $2.93 \times$ as long as wide (measured perpendicularly to vein $1-\mathrm{CU} 1+2-\mathrm{CU} 1$ ). Vein $\mathrm{r}-\mathrm{m}$ of fore wing present with a wide bulla. Vein $\mathrm{m}$-cu postfurcal. Vein $\mathrm{cu}-\mathrm{a}$ of fore wing present, postfurcal. Vein CU1a (relative to cubital vein (2-CU1) of fore wing) arising behind middle of distal vein of subdiscal cell. Vein CU1b postfurcal with m-cu. First subdiscal cell of fore wing distally closed (vein 2cu-a present). Vein 2-1A long. Hind wing vein $1-\mathrm{SC}+\mathrm{R}$ present. Subbasal cell of hind wing medium sized. Hind wing vein $\mathrm{M}+\mathrm{CU} 0.8$ times as long as vein $1-\mathrm{M}$. Hind wing vein $\mathrm{r}$ absent, $\mathrm{m}$-cu absent. Basal cell of hind wing closed, vein cu-a present. Legs: Femur not swollen. Hind coxa large, dorsally and ventrally smooth. Hind femur $3 \times$ as long as wide. Hind femur with sparse setae, its surface dorsally and ventrally smooth and finely punctate. Hind tibia $6.67 \times$ as long as wide, $2.16 \times$ as long as the hind basitarsomere length, with dense, stout and rather short setae, apically without any special patch of setae on its inner side. Hind basitarsomere $7.40 \times$ as long as maximally wide, $0.9 \times$ as long as tarsomeres $2-5$.

Metasoma. Metasoma with two sutures on carapace. Carapace fully longitudinally rugose-striate, striae protruding apically. Carapace apically emarginate. First tergite $0.73 \times$ as long as apical width, without basolateral process near base. Two median carinae present, less than or equal to a third of petiole length, median carinae widely spaced and strong. First tergite longitudinally striate over entire surface. First and second tergites fused. Surface of second tergite longitudinally striate-rugulose. Median length of second tergite $0.92 \times$ times its basal width, $1.27 \times$ as long as first tergite. Second metasomal suture straight. Third tergite longitudinally striate and rugose. Fourth to sixth tergites concealed by metasomal carapace. Carapace $2.22 \times$ as long as wide in dorsal view; ventral foramen of carapace as long as carapace, fine lamella running laterally on carapace and ending as acute curved tooth apically. Genitalia and ovipositor: ovipositor sheath $0.3 \times$ as long as metasoma. Ovipositor sheath with normal, short and thin setae.

Male. Unknown

Etymology. From the name of G.A. Brullé, a French entomologist of the XIX century who described several Neotropical Braconidae, and from the name of my friend Stéphane Brullé, who collected this new species. 


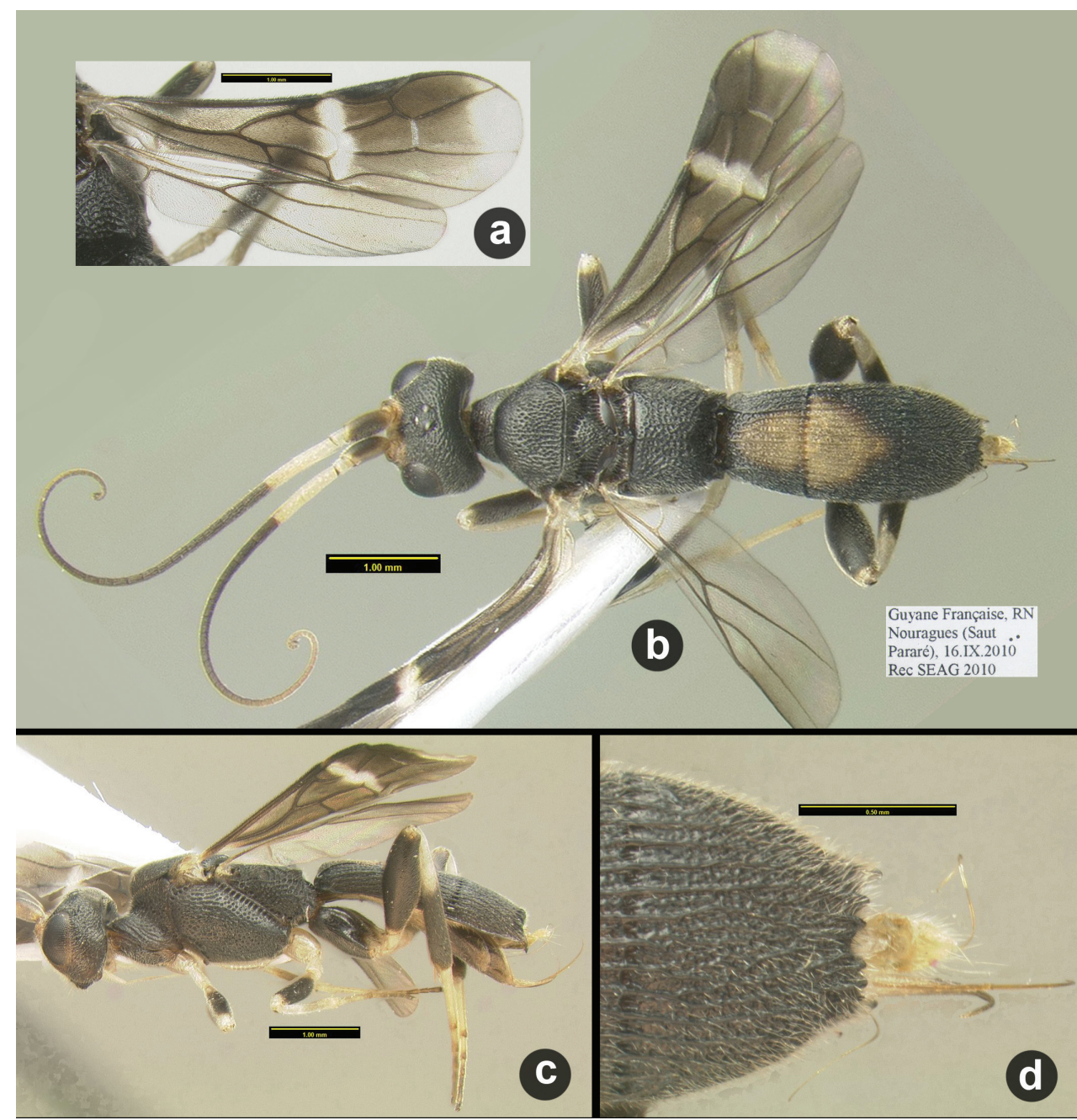

Figure I. Dentigaster brullei a Wings b Dorsal habitus c Lateral habitus $\mathbf{d}$ Apex of metasoma.

Material Examined. Holotype $q$, "Guyane française, RN Nouragues (Saut Pararé), 16.IX.2010, Rec. SEAG 2010», N4 02.368-W52 40.429. [IRSNB]

Distribution. Neotropical (French Guiana).

\section{Identification key to Dentigaster Zettel, 1990 (modified after Zettel, 1992)}

1 Carapace comparatively robust, only $2 \times$ as long as wide and $1 \times$ as long as the thorax; light brown, top of head, mesoscutum, scutellum and tergite 3 of carapace dark to black-brown, $4.2 \mathrm{~mm}$ (Argentina) ..........D. walteri Zettel

- Carapace at least $2.20 \times$ as long as broad, only rarely significantly longer than thorax, color variable 
2 Carapace very slender, $2.9 \times$ as long as wide and $1 \times$ as long as thorax; light brown, except posterior corners of mesoscutum black, $4.9 \mathrm{~mm}$ (Panama).....

D. tenuiventris Zettel

- $\quad$ Carapace at most 2.5 times as long as wide, hardly longer than thorax.........3

3 Humeral plate yellow or white, head fully or partially black........................ 4

- Humeral plate black, color of head variable ................................................5

4 Carapace entirely reticulate, head black or brown, often with some lighter patches on face, mesosoma orange, only mesoscutum sometimes partially or entirely black, carapace orange anteriorly, black posteriorly, 4.1-5.4 mm (Brazil)

D. erythrothorax Zettel

- $\quad$ Carapace with very long straight striae, head entirely black in male but face and malar space (adjacent to eyes) of female yellow, mesosoma black, except pronotum partially pale, carapace black, first and second tergites medially with one pale yellow spot, 5.0-6.0 mm (Brazil, Ecuador) .........D. albifacies Zettel

5 Head mostly black, posteroventral rim of carapace absent, apical carina present at apex of carapace, shape of carapace nearly vertical apically in lateral view, apical teeth clearly protruding posteriorly (French Guiana)....

D. brullei sp. $\mathrm{n}$.

- Head orange, posteroventral rim, apical carina, shape of carapace variable, apical teeth less protruding posteriorly and concealed below carapace in dorsal view......

Metasoma with long posteroventral rim reaching posterior two thirds of third tergite, four apical carinae present on third tergite (French Guiana)

D. warana Braet \& Fretey

- Metasoma with short posteroventral rim, apical carinae absent posteriorly (Brazil)

D. barbarella Zettel

\section{Minanga angelus Sharkey \& Braet, sp. $\mathrm{n}$.}

urn:lsid:zoobank.org:act:636EF67E-6F91-4DE6-8D31-F35C2B0A14B7

http://species-id.net/wiki/Minanga_angelus

Holotype. Female.

Diagnosis. This is the only species of Minanga lacking horns immediately posteriad the lateral ocelli; it is also the only species with horns on the lateral edges of the occiput. This species is also distinguished from other species of Minanga by the lack of fusion of hind wing veins RS and R (or SC depending on vein interpretation) and the presence of crossvein $r$ joining the two longitudinal veins.

Length. $8.2 \mathrm{~mm}$.

Color. Mostly black with some orange and yellow color. Black except as follows: propodeum light orange; fore tarsus yellow; basitarsomeres of mid and hind legs 
partly yellow; metasoma orange except apex black. Fore wing infuscate in apical half, yellow in basal half.

Head. Antenna with 43 flagellomeres; lacking horn posteriad lateral ocellus; with long sharp horn on lateral margin of occiput; vertex bulging posterolaterally; occipital carina absent; face with transverse carinae and a median longitudinal elevation; gena forming a flange posteroventrally; antennal insertions bordered by carinae laterally and medially.

Mesosoma. Pronope and subpronope well-developed; notauli smooth and reaching trans-scutal articulation; scutellar sulcus with 3 strong longitudinal carinae; posterior scutellar depression with a row of areolae; propodeum with median and lateral longitudinal carinae, and an anterior transverse carina, stub of posterior transverse carina present laterally; precoxal sulcus deep (less so anteriorly) and smooth; posterior margin of mesopleuron with several deep depressions; ventral transverse ridge present anteriad mid coxal insertions; tarsal claws with acute basal lobe; hind tarsus with long dense setae.

Metasoma. Lateral longitudinal carinae of terga 1 and 2 both narrowing posteriorly; all visible terga (3) mostly rugose, $3^{\text {rd }}$ tergum less rugose posterolaterally; ovipositor short (withdrawn under carapace).

Etymology. Named "angel" for it is the only species of Minanga lacking horns posteriad lateral ocelli, though they are cleverly hidden behind the head.

Material examined. Holotype $q$. French Guiana, RN Nouragues (Saut Pararé), 1-30.IX.2010, Rec SEAG, N4 02.368-W52 40.429. [IRSNB].

Distribution. Neotropical (French Guiana).

Phylogenetic considerations. Due to the shared derived character states of lacking an occipital carina, smooth notauli, and compressed apex of the metasoma, $M$. angelus is likely the sister-species of $M$. achterbergi (Sharkey 2004). The latter is from Mexico and is the only other species known from the New World. The new species belongs in the subgenus Anopliminanga, which was proposed by Tan and Chen (2010) to include the Chinese species, $M$. brevicarinata Tan \& Chen and the Mexican species M. achterbergi. The taxon was based on the following character states: "posterior margin of carapace without flange, dentation or depression; lateral carinae of metasomal tergite I weakly converging posteriorly; horns of head rather long, 2.4-3.7x diameter of ocellus, diverging; vein 1-SR + M of fore wing strongly curved". The authors do not support Anopliminanga with cladistic arguments. Using other sigalphine genera as outgroups and Sigalphus as the sistergroup, following Quicke et al. (2008), the dentation of the metasoma and the degree of convergence of the carinae are plesiomorphic, and the other characters are either variable within both subgenera or continuous in nature. Nonetheless the proposed subgenus appears to be monophyletic based on the nature of the sculpture of the mesopleuron. All three species have a longitudinal ridge defining the ventral margin of the precoxal groove. Likewise, members of the subgenus Minanga s.s. are likely to be monophyletic based on the derived state of dentation at the apex of the metasoma. 




Figure 2. Minanga angelus. a Lateral habitus b Wings c Dorsal head, arrow denotes occipital spine $\mathbf{d}$ Dorsal thorax e Dorsal metasoma $\mathbf{f}$ Anterodorsal head $\mathbf{g}$ Anterior head $\mathbf{h}$ Propodeum $\mathbf{i}$ Ventral metasoma, arrow denotes ovipositor.

\section{Identification key for Minanga (modified from the key of Tan et al. 2010)}

1 Posterior margin of carapace without flange, dentation or depression (subgenus Anopliminanga, Mexico, South America and China) ..........................2

- $\quad$ Posterior margin of carapace lamelliform and dentate (subgenus Minanga s. str., Afrotropical) ................................................................................ 4

2 Occipital carina absent; tergites II and III of carapace tapering to blunt apical point................................................................................................... 3

- $\quad$ Occipital carina present laterally; apex of carapace broadened posteriorly, tergites II and III reticulate-rugose; basal submedian carina short $(0.3 \times$ median length of tergite II). (China)

M. brevicarinata Tan $\&$ Chen

3 Spines vertical and positioned immediately posteriad lateral ocelli (usual position for Minanga) (Northern Mexico).

M. achterbergi Sharkey

- Spines horizontal and positioned on lateral edges of occiput (French Guiana)

.

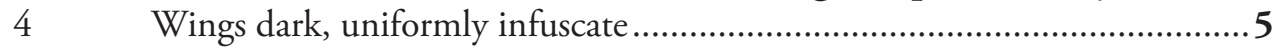




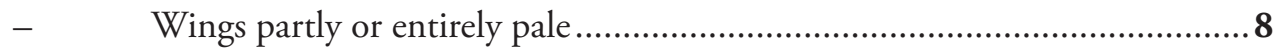

$5 \quad$ Head black; mesonotum smooth ……….................................................6

- $\quad$ Head completely or partly reddish orange; mesonotum punctate.................7

6 Postpectal carina distinct and complete; mesosoma black entirely. (Uganda).

M. phoebea Quicke

- $\quad$ Postpectal carina indistinct; mesosoma mostly reddish orange. (South Africa)

M. serrata Cameron

$7 \quad$ Head completely reddish brown; face not transversely rugose; antenna 35 segmented. (Democratic Republic of Congo)

M. oryx Saeger

- $\quad$ Head black medially and reddish brown laterally; face transversely rugose; antenna 43-44 segmented. (Madagascar)

M. seyrigi Granger

8 Head and mesosoma black, metasoma orange; legs mostly yellow; apical margin of carapace not bilobed; median lobe of mesonotum with median furrow. (South Africa)

M. flavipes Cameron

- Color of body not as above; apical margin of carapace bilobed; median lobe of mesonotum without median furrow ......................................................9

$9 \quad$ Apex of hind tibia and tarsi black. (Kenya, Tanzania) ....M. capra (Enderlein)

- $\quad$ Legs completely reddish brown or tips of tarsi brown.................................10

10 Apex of carapace excavate; color of mesonotum uniform; tips of tarsi brown. (Democratic Republic of Congo)

M. taura (Brues)

- $\quad$ Apex of carapace unexcavated; mesonotum reddish brown medially, black laterally; legs entirely reddish brown. (South Africa)

M. bimaculata Cameron

\section{Acknowledgements}

Thanks to the Société Entomologique Antilles-Guyane for providing the specimens. Support to MJS was provided by NSF grant EF-0337220.

\section{References}

Braet Y, Fretey J (1997) Species of Braconidae (Hymenoptera) collected in French Guiana with descriptions of two new species. Bulletin \& Annales de la Société Royale Belge d'Entomologie 133(3): 363-374.

Quicke DLJ, Sharkey MJ, Laurenne NM, Dowling A (2008) A preliminary molecular phylogeny of the Sigalphinae (Hymenoptera: Braconidae), including Pselaphanus Szepligeti, based on 28S rDNA, with descriptions of new Afrotropical and Madagascan Minanga and Malasigalphus species. Journal of Natural History 42(43-44):2703-2719. doi: 10.1080/00222930802364042

Sharkey MJ (2004) Afrotropical - North American disjunct distribution of Minanga (Hymenoptera: Braconidae) with the description of a new species and first record for the 
New World. Annals of the Entomological Society of America 97: 1198-1203. doi: 10.1603/0013-8746(2004)097[1198:AADDOM]2.0.CO;2

Sharkey MJ, Janzen DH (1995) Review of the world species of Sigalphus (Hymenoptera: Braconidae: Sigalphinae) and biology of Sigalphus romeroi, new species. Journal of Hymenoptera Research 4: 99-109.

Shaw MR, Quicke DLJ (1990) The biology and early stages of Acampsis alternipes (Nees), with comments on the relationships of the Sigalphinae (Hymenoptera: Braconidae). Journal of Natural History 34:611-628. doi: 10.1080/002229300299471

Tan JL, He J-H, Chen XX (2010) The Genus Minanga Cameron (Hymenoptera: Braconidae) in China, With Description of a New Subgenus and Species. Annals of the Entomological Society of America 103(3): 360-365. doi: 10.1603/AN10001

van Achterberg C (1993) Illustrated key to the subfamilies of the Braconidae (Hymenoptera: Ichneumonoidea). Zoologische Verhandelingen. No.283. 189 pp.

Zettel H (1990) Eine Revision der Gattungen der Cheloninae (Hymenoptera, Braconidae) mit Beschreibungen neuer Gattungen und Arten. Annalen des Naturhistorischen Museums in Wien. 91B:147-196.

Zettel H (1992) Zwei neue Arten aus der Gattung Dentigaster Zettel (Hymenoptera, Braconidae, Cheloninae). Deutsche Entomologische Zeitschrift 39(1-3): 131-134. doi: 10.1002/ mmnd.19920390118 